\title{
Genetic Variation and Species Identification of Thai Boesenbergia (Zingiberaceae) Analyzed by Chloroplast DNA Polymorphism
}

\author{
Jiranan Techaprasan ${ }^{1, *}$, Chatchai Ngamriabsakul ${ }^{2}$, Sirawut Klinbunga ${ }^{1,3}$, \\ Sudsanguan Chusacultanachai ${ }^{1}$ and Thaya Jenjittikul ${ }^{4}$ \\ ${ }^{1}$ National Center for Genetic Engineering and Biotechnology (BIOTEC), \\ 113 Paholyothin Road, Klong 1, Klong Luang, Pathum Thani 12120, Thailand \\ ${ }^{2}$ School of Science, Walailak University, Nakhon Si Thammarat 80160, Thailand \\ ${ }^{3}$ Center of Excellence for Marine Biotechnology, Faculty of Science, Chulalongkorn University, Bangkok 10330, Thailand \\ ${ }^{4}$ Department of Plant Science, Faculty of Science, Mahidol University, Bangkok 10400, Thailand
}

Received 2 December 2005, Accepted 13 March 2006

Genetic variation and molecular phylogeny of 22 taxa representing 14 extant species and 3 unidentified taxa of Boesenbergia in Thailand and four outgroup species (Cornukaempferia aurantiflora, Hedychium biflorum, Kaempferia parviflora, and Scaphochlamys rubescens) were examined by sequencing of 3 chloroplast (cp) DNA regions (matK, psbA-trnH and petA-psbJ). Low interspecific genetic divergence $(0.25-1.74 \%)$ were observed in these investigated taxa. The $\mathbf{5 0} \%$ majority-rule consensus tree constructed from combined chloroplast DNA sequences allocated Boesenbergia in this study into 3 different groups. Using $p s b A-1 F / p s b A-3 R$ primers, an insertion of 491 bp was observed in $B$. petiolata. Restriction analysis of the amplicon (380-410 bp) from the remaining species with Rsa I further differentiated Boesenbergia to 2 groupings; I (B. basispicata, B. longiflora, B. longipes, B. plicata, B. pulcherrima, B. tenuispicata, B. thorelii, B. xiphostachya, Boesenbergia sp.1 and Boesenbergia sp.3; phylogenetic clade A) that possesses a $R s a$ I restriction site and II ( $B$. curtisii, B. regalis, B. rotunda and Boesenbergia sp.2; phylogenetic clade $B$ and $B$. siamensis; phylogenetic clade C) that lacks a restriction site of $R s a$ I. Single nucleotide polymorphism (SNP) and indels found can be unambiguously applied to authenticate specie-origin of all investigated samples and revealed that Boesenbergia sp.1, Boesenbergia sp.2 and B. pulcherrima (Mahidol University, Kanchanaburi), B. cf. pulcherrima1 (Prachuap Khiri Khan) and B. cf. pulcherrima2 (Thong Pha Phum, Kanchanaburi) are $B$. plicata, $B$. rotunda and $B$. pulcherrima, respectively. In addition, molecular data also suggested that Boesenbergia

*To whom correspondence should be addressed.

Tel: 66-2-5646700; Fax: 66-2-5646707

E-mail: jiranan@biotec.or.th sp.3 should be further differentiated from $B$. longiflora and regarded as a newly unidentified Boesenbergia species.

Keywords: Boesenbergia, Chloroplast DNA, DNA sequencing, Genetic variation, PCR-RFLP, Species identification

\section{Introduction}

Boesenbergia, a member of Zingiberaceae, are composed of approximately 80 species worldwide and 19 of which are indigenous to Thailand (Saensouk and Larsen, 2001). Only $B$. rotunda is cultivated commercially and its rhizomes have been used for medicinal (i.e. treatment of colic disorder and as an aphrodisiac in folk medicine; Trakoontivakorn et al., 2001) and culinary purposes. The rhizomes of this species contain active constituents against HIV-1 protease (Tewtrakul et al., 2003) and those exhibiting anti-tumor, anti-mutagenic and anti-inflammatory activities (Murakami et al., 1994; Trakoontivakorn et al., 2001; Tuchinda et al., 2002). Due to these properties, Boesenbergia species has gained attention as important sources of active constituents for medicinal treatment.

Reproductive parts (e.g. anther crests, labellum and inflorescence position) play an important role for taxonomy of Boesenbergia. Therefore, taxonomic identification of these species based primarily on morphological characters without reproductive parts, is not sufficient for species identification. However, Boesenbergia possesses the dormancy period from the end of December to the middle of May. The flowering season of Boesenbergia is short, and some species have similar floral morphology, but differ in colors and inflorescence positions.

One of our purposes is to identify and characterize 
metabolic profiles of Boesenbergia species where no data are available at present. Nevertheless, Boesenbergia display systematic problems owing to morphological variation at the intraspecific level. For instance, B. curtisii can possess black or white leaf sheaths and B. plicata can have yellow or red flowers (Vanijajiva et al., 2003). Typically, external characteristics are influenced by a variety of habitats and environmental conditions. Accordingly, two sympatric species may be morphologically similar and misidentified as a single species. Conversely, allopatric taxa in different habitats may show ecomorphological variation and have questionable species status. Authentication of Boesenbergia in Thailand by molecular markers is thus required to unambiguously identify the correct species of different forms of plant materials.

The basic information on genetic diversity and systematics of Boesenbergia is rather limited. Vanijajiva et al. (2003) examined 11 taxa of Boesenbergia, 6 taxa of Kaempferia and 2 taxa of Scaphochlamys using isozyme analysis. Peroxidase (POX), superoxide dismutase (SOD), glutamate dehydrogenase $(\mathrm{GDH})$ and malate dehydrogenase (MDH) yielded polymorphic patterns across investigated taxa. A UPGMA dendrogram and a principal component analysis showed closer intergeneric relationships between Boesenbergia and Scaphochlamys than Kaempferia. Results were subsequently confirmed by randomly amplified polymorphic DNA (RAPD) analysis (Vanijajiva et al., 2005).

Polymorphism of chloroplast DNA (cpDNA), especially trnK, $m a t K$, and an intergenic $t r n L-t r n F$, has been commonly used for phylogenetic studies of various plants (Shaw et al., 2005). The mat $K$ which is the most rapidly evolving coding region in the chloroplast genome, has successfully been used for phylogenetic analysis at lower taxonomic levels in Saxifraga (Soltis et al., 1996) and Chrysosplenium (Soltis et al., 2001), Saxifragaceae, Paeonia, Paeoniacae (Sang et al., 1997), Linanthus, Polemoniaceae (Bell and Patterson, 2000), Lycium, Solanaceae (Fuguda et al., 2001), Clintonia, Liliaceae (Hayashi et al., 2001), Coelogyne, Orchidaceae (Gravendeel et al., 2001), Myosotis, Boraginaceae (Winkworth et al., 2002), Hordeum, Poaceae (Nishikawa et al., 2002), and Hypochaeris, Asteracae (Samuel et al., 2003). Within Zingiberaceae, trnK was used for identification of Curcuma species (Cao et al., 2001) while $\operatorname{trnK}$ (including matK) in combination with nuclear internal transcribed spacer (ITS) were used to study triploid formation in Globba (Takano and Okada, 2002). Recently, $m a t K$ was used to examine phylogenetic relationships of Zingiberaceae (Kress et al., 2002) and weakly supported a monophyly of Boesenbergia (54\% bootstrap value).

More recently, intergenic spacers (i.e. $p s b A$-trnH and petA$p s b J)$ have been increasingly used for studies of genetic variation and phylogenetic analysis due to their less functional constraint than coding regions (Shaw et al., 2005). The psbA$\operatorname{trnH}$ spacer has been proposed as the target DNA region for identifying Angiosperm species by using short orthologous DNA sequences (DNA barcodes) (Kress et al., 2005) while petA-psbJ spacer is a new cpDNA region used for studies of
Musa balbisiana phylogeny (Swangpol, 2004) and phylogeography of Trochodendron aralioides (Huang et al., 2004). Therefore, these intergenic spacers in combination with mat $K$ were applied for examination of genetic diversity and phylogeny of Thai Boesenbergia.

The objectives of this study are to evaluate genetic variation and phylogenetic relationships of Boesenbergia in Thailand and to identify molecular markers that can be used for identifying species origin of these taxa. The basic information can then be practically applied to partially resolve taxonomic identification of Boesenbergia in Thailand.

\section{Materials and Methods}

Sampling. Twenty-two Boesenbergia taxa, representing 14 recognized species and 3 taxa (Boesenbergia sp.1-3) that could only be differentiated at the generic level were sampled (Table 1 and Fig. 1). These represent all four sections according to Loesener's (1930) classification. A representative of 4 closely related taxa (Cornukaempferia aurantiflora, Hedychium biflorum, Kaempferia parviflora, and Scaphochlamys rubescens) of Boesenbergia were included as outgroup references.

DNA extraction. Total DNA was extracted from fresh young leaves using a modification of the CTAB method of Doyle and Doyle (1987). After an addition of isopropanol, the precipitated DNA was gently hooked out with a pipette tip, placed in a new microcentrifuge tube, and washed with $70 \%$ ethanol. DNA was airdried and resuspended in TE $(10 \mathrm{mM}$ Tris- $\mathrm{HCl}, \mathrm{pH} 8.0,0.1 \mathrm{mM}$ EDTA). The concentration of extracted DNA was spectrophotometrically determined (Sambrook and Russell, 2001).

Polymerase chain reaction (PCR) and DNA sequencing. The matK, psbA-trnH, and petA-psbJ/psbL regions of each taxa were separately amplified in a 50-ml reaction volume containing $10 \mathrm{mM}$ Tris- $\mathrm{HCl}, \mathrm{pH} 8.8,50 \mathrm{mM} \mathrm{KCl}, 0.8 \%$ nonidet $\mathrm{P} 40$, appropriate $\mathrm{MgCl}_{2}$ (4.0, 2.5 and $4.0 \mathrm{mM}$ for matK, psbA-trnH, and petA-psbJ/ $p s b L$, respectively), dNTPs $(0.28,0.20$ and $0.24 \mathrm{mM})$, primers (0.28 mM each of matKTI-1F; 5'-GTA GAG TCT ATA AGA CCA CGA-3' and matKTI-1R; 5'-CAC GAC TTT CCC TAT GTA TAC3', $0.20 \mathrm{mM}$ each of $p s b A-1 \mathrm{~F}$; 5'-CTT GGT ATG GAA GTA ATG CA-3' and trnH-1R; 5'-ATC CAC TTG GCT ACA TCC G-3', and $0.24 \mathrm{mM}$ each of petA-F; 5'-AGG TTC AAT TGT MCG AAA TG3 ' and $p s b J-\mathrm{R}$; 5'-CTG GAA GRA TTC CTC TTT GG-3' or $p s b L$ R; 5'-GTA CTT GCT GTT TTA TTT TC-3'; Fig. 2), total DNA (600-800, 200-400 and 200-400 ng, respectively) and $1 \mathrm{U}$ of Taq DNA polymerase. PCR were carried out consisting an initial denaturation step at $94^{\circ} \mathrm{C}$ for $3 \mathrm{~min}$ followed by 35 cycles of denaturation $\left(94^{\circ} \mathrm{C}\right.$ for $\left.1 \mathrm{~min}\right)$, annealing $\left(49,50\right.$ or $58^{\circ} \mathrm{C}$ for $\left.1 \mathrm{~min}\right)$, and extension $\left(72^{\circ} \mathrm{C}\right.$ for 3,1 or $\left.1 \mathrm{~min}\right)$. The final extension was carried out at $72^{\circ} \mathrm{C}$ for $10 \mathrm{~min}$. PCR products were sequenced for both directions on an automated DNA sequencer using the original amplification primer as the sequencing primer except for sequencing of the $5^{\prime}$ terminus of $m a t K$ where TA-10F (5'-GAA GAT AGA TCT CGG CAA C-3'; Takano and Okada, 2002) and matK-R (5'-TTA CAT AAA AAT GTA TTC GCT C-3') were used. 
Table 1. Species and geographic origins of Boesenbergia and outgroup references used in this study

\begin{tabular}{|c|c|c|}
\hline Species & Geographic location & Remark \\
\hline B. basispicata K. Larsen ex P. Sirirugsa & Nakhon Si Thammarat, PEN & $2 \mathrm{n}=20$ (Augsonkitt et al., 2004) \\
\hline B. curtisii (Bak.) Schltr. & Krabi, PEN & $2 \mathrm{n}=24($ Eksomtramage and Boontum, 1995) \\
\hline B. curtisii (Bak.) Schltr. & Nakhon Si Thammarat, PEN & \\
\hline B. longiflora (Wall.) Kuntze & Tak, N & \\
\hline B. longiflora (Wall.) Kuntze & Phetchabun, NE & \\
\hline B. longipes (Ridl.) Schltr. & Ranong, PEN & $2 \mathrm{n}=20($ Eksomtramage et al., 2002) \\
\hline B. longipes (Ridl.) Schltr. & Nakhon Si Thammarat, PEN & \\
\hline B. petiolata P. Sirirugsa & Saraburi, C & \\
\hline B. plicata (Ridl.) Holttum & Krabi, PEN & $\begin{array}{l}2 \mathrm{n}=20(\text { Eksomtramage et al., 1996), } \\
\text { red flowers }\end{array}$ \\
\hline B. plicata (Ridl.) Holttum & Krabi, PEN & $\begin{array}{l}2 \mathrm{n}=20 \text { (Eksomtramage et al., } 1996 \text { and } \\
\text { Eksomtramage et al., 2002), yellow flowers }\end{array}$ \\
\hline B. prainiana (Bak.) Schltr. & Narathiwat, PEN & $2 \mathrm{n}=20($ Eksomtramage et al., 1996) \\
\hline B. pulcherrima (Wall.) Kuntze & Kanchanaburi, SW & \\
\hline B. cf. pulcherrima 1 & Prachuap Khiri Khan, SW & \\
\hline B. cf. pulcherrima 2 & Kanchanaburi, SW & \\
\hline B. regalis $\mathrm{B}$. Kharukanant \& $\mathrm{S}$. Tohdam & Narathiwat, PEN & \\
\hline B. rotunda (L.) Mansf. & Not known & $\begin{array}{l}\text { Thai common name 'Krachai Dang' } \\
\text { (cultivated specimen) }\end{array}$ \\
\hline B. rotunda (L.) Mansf. & Prachin Buri, SE & orange rhizomes \\
\hline B. rotunda (L.) Mansf. & Chiang Mai, $\mathrm{N}$ & $\begin{array}{l}2 \mathrm{n}=36(\text { Eksomtramage and Boontum, 1995), } \\
\text { yellow rhizomes }\end{array}$ \\
\hline B. siamensis (Gagnep.) P. Sirirugsa & Kanchanaburi, SW & \\
\hline B. tenuispicata $\mathrm{K}$. Larsen & Krabi, PEN & $2 \mathrm{n}=20$ (Augsonkitt et al., 2004) \\
\hline B. thorelii (Gagnep.) Loes. & Not known & cultivated specimen \\
\hline B. xiphostachya (Gagnep.) Loes. & Mukdahan, NE & $2 \mathrm{n}=20($ Eksomtramage et al., 2002) \\
\hline Boesenbergia sp.1 & Nakhon Si Thammarat, PEN & \\
\hline Boesenbergia sp. 2 & Uthai Thani, SW & variegated leaf \\
\hline Boesenbergia sp.3 & Tak, N & \\
\hline Cornukaempferia aurantiflora J. Mood \& K. Larsen & Phitsanulok, N & \\
\hline Hedychium biflorum P. Sirirugsa \& K. Larsen & Tak, N & \\
\hline Kaempferia parviflora Wall. & Nakhon Ratchasima, E & \\
\hline Scaphochlamys rubescens Jenjitt. \& K. Larsen & Narathiwat, PEN & \\
\hline
\end{tabular}

$\mathrm{N}=$ Northern, $\mathrm{NE}=$ North-eastern, $\mathrm{C}=$ Central, $\mathrm{E}=$ Eastern, $\mathrm{SE}=$ South-eastern, $\mathrm{SW}=$ South-western, $\mathrm{PEN}=$ Peninsular Thailand.

PCR-restriction fragment length polymorphism (RFLP) of a partial psbA-trnH spacer. Nucleotide sequences of a $p s b A-t r n H$ spacer of Boesenbergia and outgroups generated from $p s b A-1 \mathrm{~F}$ and trnH-1R were aligned using BioEdit version 7.0.5.2 (Hall, 1999). A new reverse primer ( $p s b A$-3R; 5'-CAA GAA ACG ATA ATA AAT CTC G-3') was designed and tested against all investigated taxa. The amplification reaction was carried out in a $25-\mu 1$ reaction volume containing $10 \mathrm{mM}$ Tris- $\mathrm{HCl}, \mathrm{pH} 8.3,50 \mathrm{mM} \mathrm{KCl}, 1.5 \mathrm{mM}$ $\mathrm{MgCl}_{2}, 100 \mu \mathrm{M}$ of each dNTP, $0.2 \mu \mathrm{M}$ of each primer, $0.3 \mathrm{U}$ of Taq DNA polymerase and $100 \mathrm{ng}$ of DNA template. PCR was carried out using a touchdown profile involving predenaturation at $94^{\circ} \mathrm{C}$ for $3 \mathrm{~min}$ followed by 2 cycles of denaturation at $94^{\circ} \mathrm{C}$ for $45 \mathrm{~s}$, annealing at $68^{\circ} \mathrm{C}$ for $1 \mathrm{~min}$ and extension at $72^{\circ} \mathrm{C}$ for $30 \mathrm{~s}, 9$ cycles of the same profile with the exception that an annealing temperature was lowered for $2^{\circ} \mathrm{C}$ every 3 cycles and 28 cycles of the annealing temperature of $60^{\circ} \mathrm{C}$. The final extension was performed at $72^{\circ} \mathrm{C}$ for $7 \mathrm{~min}$. The PCR product was restricted with $R s a \mathrm{I}$ (GTAC) at $37^{\circ} \mathrm{C}$ for $2.5 \mathrm{hrs}$. The digests were size-fractionated through $2.0 \%$ agarose gels prepared in $0.5 \mathrm{X}$ TBE, stained with ethidium bromide, and visualized under a UV transilluminator (Thaewnon-ngiw et al., 2004).

Phylogenetic analysis. Sequences were edited and aligned using BioEdit. The divergence between pairs of sequences was calculated using a Kimura (1980) 2-parameter model without indel consideration. For phylogenetic reconstruction, all three cpDNA sequence data were combined. Indels were accounted in the analysis ( 1 for insertion and 0 for deletion). Maximum parsimony analysis was carried out using a Phylogenetic Analysis Using Parsimony (PAUP*) software, version 4.0 Beta 10 (Swofford, 2004). The most parsimonious trees were obtained through the heuristic search option with 1000 random sequence addition. Bootstrapping (1000 replicates) was performed to assess levels of support for individual clades using the heuristic search with random sequence addition. 

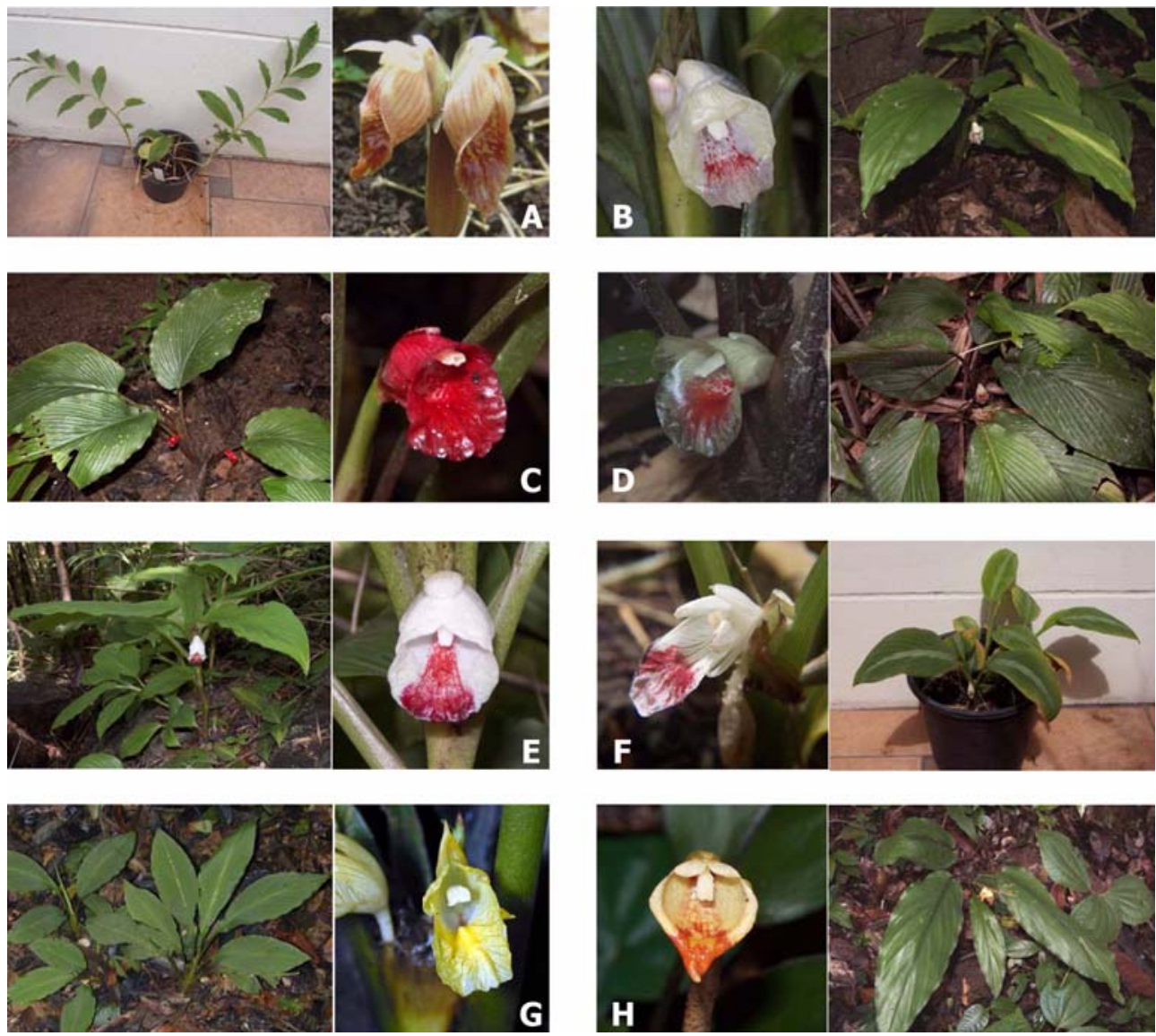

Fig. 1 External morphology of some Boesenbergia species in Thailand; B. siamensis (A), B. petiolata (B), B. plicata (red flowers, C), B. plicata (yellow flowers, D) B. pulcherrima (E), Boesenbergia sp.2 (variegated leaf, F), B. regalis $(\mathrm{G})$ and B. tenuispicata $(\mathrm{H})$.

(A) 5 'trnK

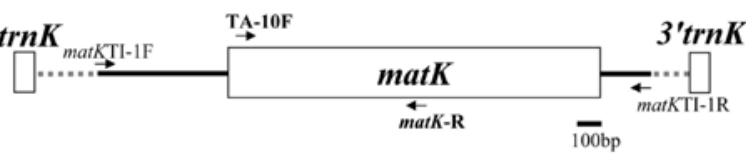

(B)

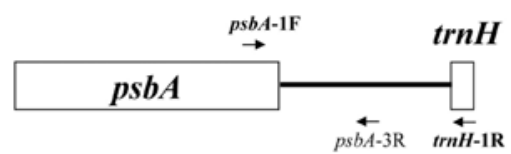

(C)

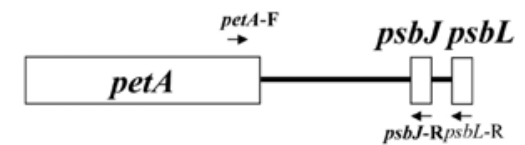

Fig. 2 Schematic diagrams illustrating positions of primers used for amplification and/or sequencing (boldface) of matK (A), psbA-trnH (B) and petA-psbJ/psbL (C) chloroplast DNA regions of Boesenbergia and outgroup references.

\section{Results}

The amplification products of matK, psbA-trnH, petA-psbJ and petA-psbL in Thai Boesenbergia were approximately 2.5 $\mathrm{kb}, 800 \mathrm{bp}, 1.0 \mathrm{~kb}$ and $1.2 \mathrm{~kb}$, respectively. The number of nucleotides after multiple alignments was 701 (B. prainiana) 710 (B. longiflora, B. longipes, B. petiolata, B. plicata, B. regalis and $B$. rotunda) for $m a t K, 714 \mathrm{bp}$ (B. curtisii) - $750 \mathrm{bp}$ (B. longipes) for psbA-trnH and $620 \mathrm{bp}$ (B. curtisii) - $667 \mathrm{bp}$ (B. tenuispicata) for petA-psbJ (Table 2). A 491 bp insertion was observed in a psbA-trnH spacer of $B$. petiolata.

Multiple alignments yielded the combined nucleotide sequences of $2803 \mathrm{bp}$ in length. A total of 145 variable sites were found. These contained 45 phylogenetically informative characters, and 17 informative indels. Limited genetic diversity was observed from each chloroplast region (Table 2) resulting in low interspecific sequence divergence $(0.25-1.74 \%)$ between Boesenbergia species. For species having replicate specimens, the intraspecific genetic variability was observed in $B$. longiflora $(0.54 \%)$, B. plicata $(0.05-0.10 \%)$, B. pulcherrima (0.00-0.15\%) and B. rotunda $(0.00-0.20 \%)$ but not in $B$. curtisii and B. longipes.

Polymorphic nucleotide sequences of matK, psbA-trnH, and petA-psbJ between Boesenbergia revealed species-specific orthologous markers in all investigated taxa (Table 3). Species origins of taxonomically unidentified Boesenbergia sp.1 and Boesenbergia sp.2, were confirmed to be B. plicata and $B$. rotunda while B. pulcherrima (Mahidol University, Kanchanaburi) 
Table 2. Sequence characteristics and nucleotide sequence divergence of matK, psbA-trnH, and petA-psbJ across Boesenbergia species and outgroup references

\begin{tabular}{lcccc}
\hline & matK & psbA-trnH & petA-psbJ & combined data \\
\hline Number of nucleotides & $701-710$ & $714-1252$ & $620-667$ & 2803 \\
Number of variable sites & 45 & 49 & 51 & 145 \\
Number of informative characters & 16 & 19 & 10 & 45 \\
Number of informative indels & 3 & 7 & 7 & 17 \\
Percentage of interspecific and & $0.15-1.72$ & $0.00-3.53$ & $0.00-2.53$ & $0.25-1.74$ \\
intergeneric sequence divergence* & & & \\
Percentage of intraspecific sequence & & & \\
divergence & 0.00 & 0.00 & 0.00 & 0.00 \\
B. curtisii & 0.44 & 0.83 & 0.31 & 0.54 \\
B. longiflora & 0.00 & 0.00 & 0.00 & 0.00 \\
B. longipes & 0.00 & $0.00-0.14$ & $0.00-0.16$ & $0.05-0.10$ \\
B. plicata & $0.00-0.45$ & 0.00 & 0.00 & $0.00-0.15$ \\
B. pulcherrima & 0.00 & $0.00-0.14$ & $0.00-0.65$ & $0.00-0.20$ \\
B. rotunda & & & \\
\hline
\end{tabular}

${ }^{a}$ An insertion of 491 bp was found in B. petiolata, *indels were not included in the analysis

and B. cf. pulcherrimal (Prachuap Khiri Khan) and B. cf. pulcherrima2 (Thong Pha Phum, Kanchanaburi) exhibiting floral variation (Fig. 3) were all recognized as B. pulcherrima. In addition, morphologically similar Boesenbergia sp. 3 and $B$. longiflora displayed different species-diagnostic sequences.

Phylogenetic analysis based on the combined sequences of matK, psbA-trnH and petA-psbJ generated 96 most parsimonious trees with the equal length of 208 steps and consistency (CI) and retention (RI) indices of 0.72 and 0.83 , respectively. A $50 \%$ majority-rule consensus tree divided Boesenbergia into 3 groups including: A (B. longiflora, B. basispicata, $B$. tenuispicata, $B$. prainiana, $B$. plicata, $B$. longipes, $B$. xiphostachya, B. petiolata, B. pulcherrima, B. thorelii, Boesenbergia sp.1 and Boesenbergia sp.3), B (B. curtisii, B. rotunda, $B$. regalis and Boesenbergia sp.2) and $\mathrm{C}$ (B. siamensis). Identical Boesenbergia species originating from different geographic locations were phylogenetically clustered together with significant bootstrapping values (Fig. 4).

Considering nucleotide sequences of a partial psbA-trnH spacer, an insert of CTT(A/C/T)GTGTA was found in all Boesenbergia allocated into the clade A but not B and $\mathrm{C}$. Additionally, the $5^{\prime}$ adjacent region of an insertion possesses an $R s a$ I recognition site allowing the development of PCRRFLP to differentiate Boesenbergia lineages (the presence of restriction site; clade $\mathrm{A}$ and the absence of restriction site; clades B and C) derived from phylogenetic analysis of the chloroplast DNA sequences (Fig. 5).

\section{Discussion}

Boesenbergia is one of the systematically problematic genera in Zingiberaceae. Taxonomy of these species relied based primarily on external morphology. Authentication of Boesenbergia is rather difficult due to heterogeneity of external morphology at both intraspecific and interspecific levels. In the present study, the reliable molecular taxonomic key of Boesenbergia in Thailand was successfully developed based on polymorphism of $m a t K, p s b A$-trnH and petA-psbJ.

Limited sequence divergence of the partial matK was observed at both interspecific and intergeneric levels $(0.15-$ $1.72 \%, 16$ informative sites and 3 indels). Apparently, informative characters and indels of matK in Boesenbergia are lower than those in Globba (37 informative sites and 9 indels; Takano and Okada, 2002) and other genera. This suggested that polymorphism of matK may not be sufficient to differentiate all investigated taxa in this study. Subsequently, psbA-trnH and petA-psbJ intergenic spacers were included and revealed slightly greater divergence between investigated taxa (0.00-3.53\% and $0.00-2.53 \%$ with additional 26 and 17 informative sites/indels, respectively).

Kress et al. (2005) proposed ITS and trnH-psbA intergenic spacer to be potentially usable DNA regions for species identification using polymorphic DNA sequences (DNA barcodes) to facilitate biodiversiy studies of 99 plant species belonging to 80 genera of 53 families.

Likewise, nucleotide sequences of the combined chloroplast DNA revealed informative sites and indels that can be used for species diagnosis of Thai Boesenbergia in this study unambiguously and is reported for the first time here. Several taxa, for instance Boesenbergia sp.1 and Boesenbergia sp.2, were able to morphologically identify only at the generic level. Using species-diagnostic sequences found in this study, these taxa were recognized as an ecomorphological variant of $B$. plicata and B. rotunda, respectively. Additionally, $B$. cf. pulcherrima inferred from leafy shoots and storage roots were collected without the reproductive parts from Prachuap Khiri Khan (peninsular Thailand) and Kanchanaburi (south-western 


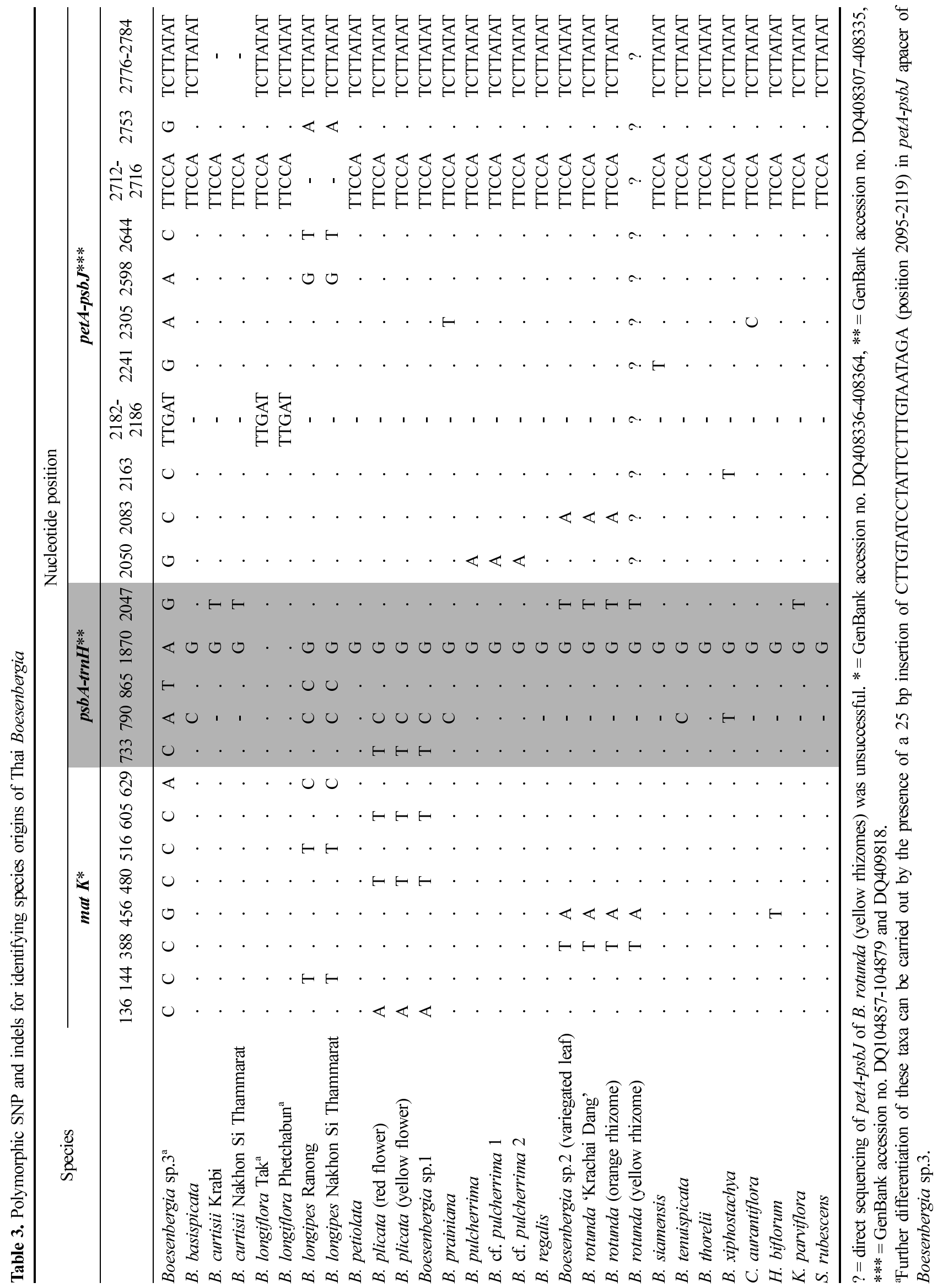



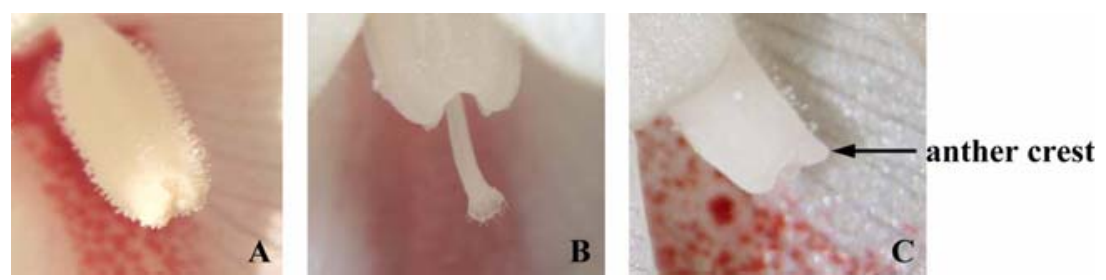

Fig. 3 Morphological variation of B. pulcherrima originating from Mahidol University, Kanchanaburi (A) and Prachuap Khiri Khan (B) that lack the anther crests and that originating from Thong Pha Phum, Kanchanaburi (C) that possesses the anther crests. They are regarded as B. pulcherrima based on species-diagnostic sequences of matK, psbA-trnH, and petA-psbJ (see text for detailed information).

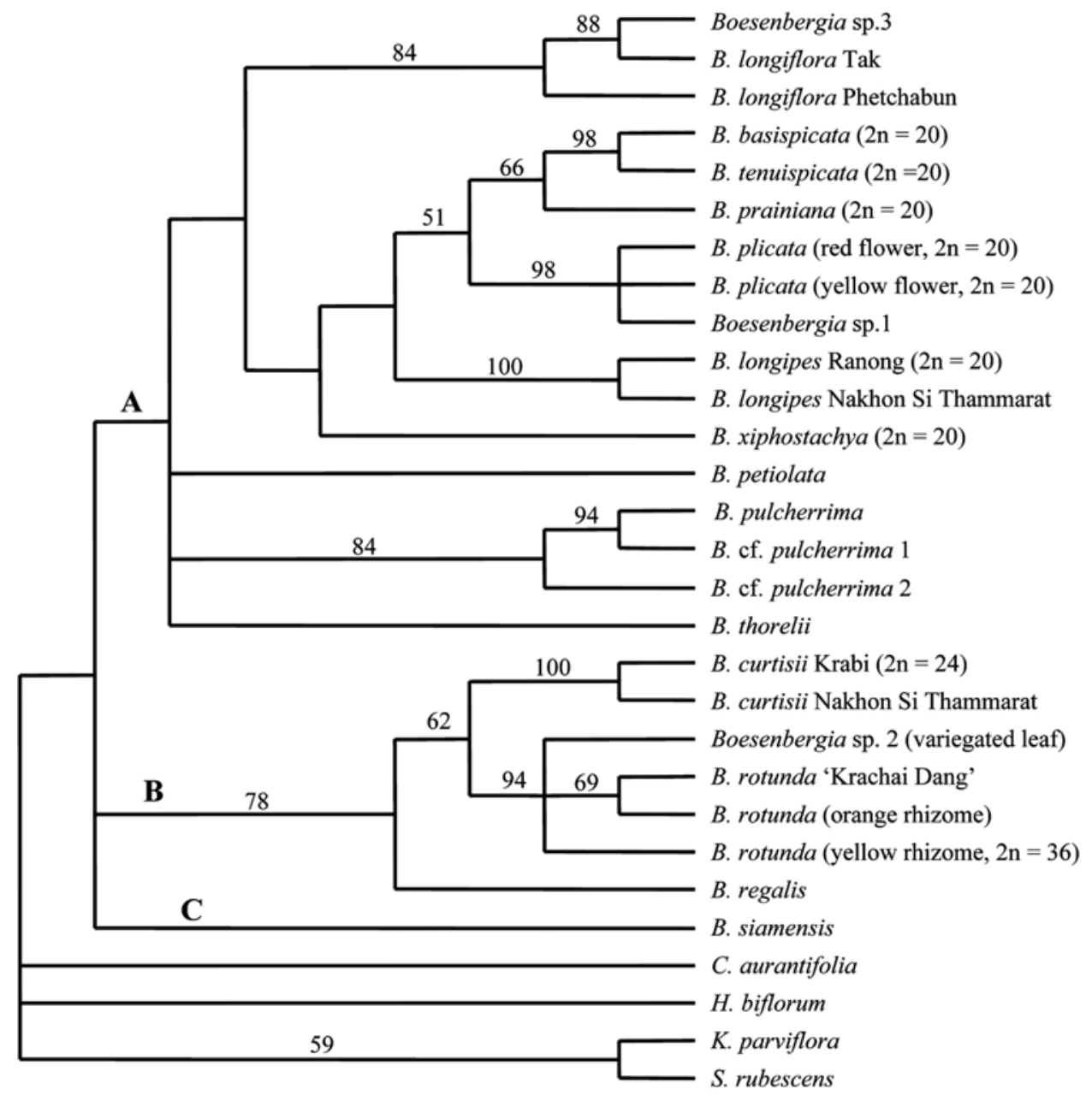

Fig. 4 A 50\% majority-rule consensus tree constructed from the 96 most parsimonious trees based on combined $m a t K$, $p s b A$-trnH, and petA-psbJ sequences (tree length $=208$ steps; consistency index, $\mathrm{CI}=0.72$ and retention index, $\mathrm{RI}=0.83)$. Values at the node $(>50 \%)$ represent the percentage of times that the particular node occurred in 1000 replicates generated by bootstrapping the original sequences. Differentiation between lineages were compatible with the chromosome numbers $(2 n=20$ for members of clade A and $2 n=24$ and 36 for those of clade B).

Thailand). They are B. pulcherrima according to speciesspecific sequences of the chloroplast DNA. Owing to our finding, SNP-based PCR assays can be further developed to simplify the detection method from DNA sequencing to allele-specific polymerase chain reaction (Moorhead et al., 2003 and Miles et al., 2004).
The external characteristics of the anther crests have been used for classification of Boesenbergia. For example, $B$. pulcherrima has crest bilobed, shortly extended beyond thecae (Sirirugsa, 1992). The vegetative parts of this presumptive species were collected from 3 different geographic locations and cultivated. Two of which lacked the anther crests (Fig. 3). 


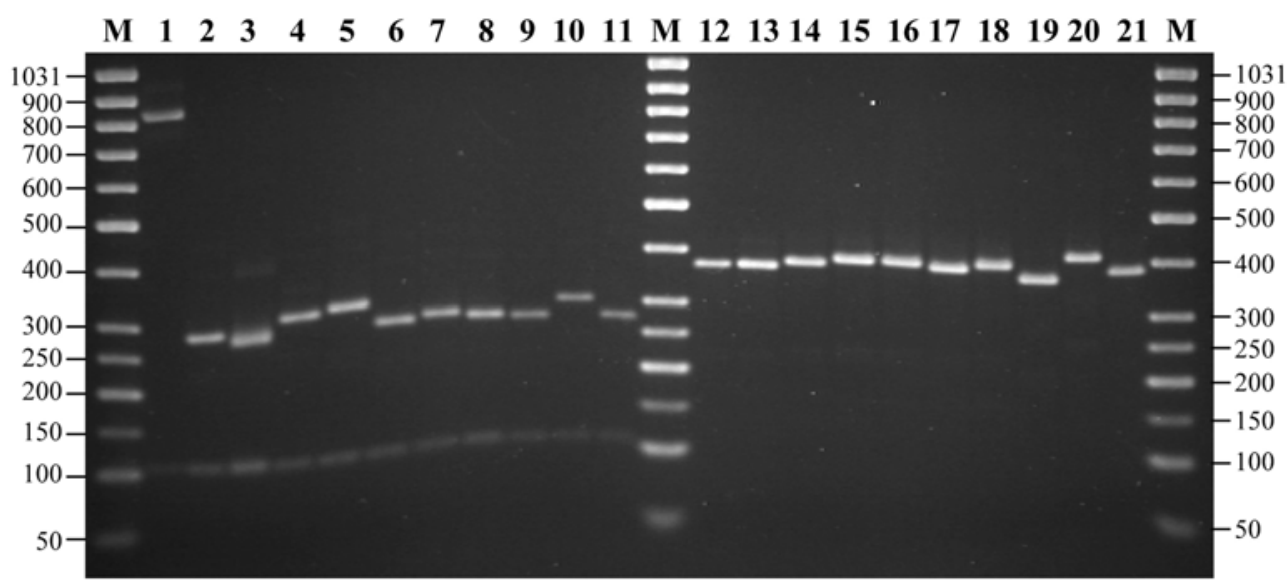

Fig. 5 Agarose gel electrophoresis illustrated restriction analysis of RsaI-digested partial psbA-trnH spacer of B. petiolata (lane 1), Boesenbergia sp.3 (lane 2), B. basispicata (lane 3), B. longiflora (lane 4), B. longipes (lane 5), B. plicata (lane 6), B. prainiana (lane 7), B. pulcherrima (lane 8), B. tenuispicata (lane 9), B. thorelii (lane 10), B. xiphostachya (lane 11), B. curtisii (Krabi, lane 12), B. curtisii (Nakhon Si Thanmmarat, lane 13), B. regalis (lane 14), Boesenbergia sp.2 (variegated leaf, lane 15), B. rotunda ('Krachai Dang, lane 16), B. siamensis (lane 17), C. aurantiflora (lane 18), H. biflorum (lane 19), K. parviflora (lane 20) and S. rubescens (lane 21). A 50 bp ladder (lanes $\mathrm{M}$ ) was included as the DNA marker.

Floral morphology and species-diagnostic sequences of these plants suggested that they are B. pulcherrima. This illustrated that the anther crests cannot be used for identification of $B$. pulcherrima.

According to external morphology, Boesenbergia sp.3 was B. longiflora-like. Nevertheless, flowers of Boesenbergia sp.3 are straw-colored, with the strongly crinkled labellum margin whereas those of $B$. longiflora are white to pink, with the faintly undulated labellum margin (K. Larsen, personal communication). Species-specific nucleotide sequences deduced from $m a t K, p s b A$-trnH and petA-psbJ polymorphism indicating that Boesenbergia sp. 3 is not B. longiflora but it should have been a newly unidentified Boesenbergia species in Thailand. In contrast, informative sequences of Boesenbergia species exhibiting intraspecific morphological variation (e.g. in $B$. rotunda or $B$. plicata exhibiting different rhizome or flower colors) were perfectly identical confirming the species status of allopatric taxa.

Vanijajiva et al. (2003 and 2005) examined phylogenetic relationships between 11 Boesenbergia taxa representing 8 extant species using isozyme (POX, SOD, GDH and MDH) and RAPD (OPB-14, OPAM-01, OPAM-03, OPAM-12, and OPZ-03) analyses. UPGMA dendrograms constructed from genetic similarity in their studies were comparably separated overall investigated taxa to 2 different groups; A ( $B$. basispicata, B. prainiana, B. pulcherrima and B. tenuispicata) and B (B. rotunda and B. curtisii). Nevertheless, B. longipes (RAPD) and B. plicata (isozymes and RAPD) were allocated in the same group of $B$. rotunda $(2 \mathrm{n}=36)$ and $B$. curtisii $(2 \mathrm{n}=$ 24) while results from $m a t K, p s b A-t r n H$, and petA-psbJ sequences clearly allocated these taxa which possess $2 \mathrm{n}=20$, to a different phylogenetic lineage.

Notably, the inheritance of cpDNA is usually uniparental and effectively haploid. Therefore, studies of cpDNA polymorphism cannot be used to examine genetic contribution by the other parental lineage. However, the effective population size estimated from cpDNA is generally smaller than that estimated from nuclear markers such as allozymes and nuclear DNA (Birky et al., 1989). This increases the effects of genetic drift and the rate of turnover within populations which provides more rapid sorting of ancestral alleles within and between species than nuclear DNA markers (Dowling, 1996). Moreover, slightly differences of the detail grouping between Boesenbergia previously reported by Vanijajiva et al. 2003 and 2005 and this study may have resulted from the use of molecular markers exhibiting different evolutionary rates (e.g. between protein and DNA markers and between nuclear and organelle DNA) and/or different approaches (isozyme electrophoresis, RAPD-PCR and DNA sequencing).

Interestingly, phylogenetic analysis based on matK, $p s b A$ trnH and petA-psbJ polymorphism allocated Boesenbergia species to 3 separate groups which are concordant with inflorescence types; A (elongated inflorescences), B (compact inflorescences) and C (B. siamensis in which the inflorescence appears before leafy shoots after the dormancy period). The somatic chromosome numbers of previously characterized Boesenbergia species possessed the chromosome number of $2 \mathrm{n}=20$ were allocated into the clade A whereas $B$. curtisi and $B$. rotunda possessed $2 \mathrm{n}=24$ and $2 \mathrm{n}=36$ were allocated to the clade B, respectively (Eksomtramage and Boontum, 1995; Eksomtramage et al., 1996; Eksomtramage et al., 2002 and Augsonkitt et al., 2004). This suggested the existence of evolutionarily separated lineages in Boesenbergia as previously reported based on the combined ITS and matK region sequence data (Kress et al., 2002) and ITS and trnL-trnF (Ngamriabsakul et al., 2003). Therefore, it is interesting to examine whether the chromosome numbers of Boesenbergia 
sp. 1, 2 and 3 and the remaining uninvestigated Thai Boesenbergia reflected evolutionary lineages found in this study.

Kress et al. (2002) studied phylogenetic relationships of 3 species of Boesenbergia (B. rotunda\#1 and \#2, B. pulcherrima and $B$. longiflora\#1 and \#2) and all genera of the Zingiberaceae and found that Boesenbergia were paraphyletic when genetically analyzed by ITS but possibly monophyletic by matK sequence data. Although the monophyly of Boesenbergia cannot be concluded by our results (only other four related genera were included in the analysis), all investigated Boesenbergia taxa clustered together. The use of all related genera and an outgroup outside Zingiberaceae would clarify the phylogenetic controversy of Boesenbergia.

Our present study illustrated the use of matK, psbA-trnH and pet $A-p s b J$ polymorphism to examine intra- and interspecific variability, phylogenetic relationships and species-diagnostic markers to assist taxonomic identification of Thai Boesenbergia. Lineage-specific detection by PCR-RFLP and species-specific sequences found in this study can be directly applied for authentication of fresh or dried plant materials to ensure reliable botanical sources of metabolic profiling studies of these species.

Acknowledgments We gratefully thank Prof. Dr. Yodhathai Thebtaranonth and Dr. Lawrence A. Alice for their critical comments on this project. We would also like to acknowledge Areeya Palang, Kannika Khetpu, and Supaporn Thumrungtanakit for their laboratory assistance. This research was supported by the Thailand Research Funds (TRF) and the National Center for Genetic Engineering and Biotechnology (BIOTEC), under the Bioresource Utilization Program of the Biodiversity Research and Training Program (BRT); grant number BUP001G-46 and BUP009G-47.

\section{References}

Augsonkitt, A., Eksomtramage, L. and Sirirugsa, P. (2004) Chromosome numbers of some Zingiberaceae in Thailand. Songklanakarin J. Sci. Technol. 26, 549-557.

Birky, C. W., Jr., Furest, P. and Maruyama, T. (1989) Organelle gene diversity under migration, mutation and drift: equilibrium expectations, approach to equilibrium, effects of heteroplasmic cells, and comparison to nuclear genes. Genetics 121, 613-627.

Bell, C. D. and Patterson, R. W. (2000) Molecular phylogeny and biogeography of Linanthus (Polemoniaceae). Am. J. Bot. 87, 1857-1870.

Cao, H., Sasaki, Y., Fushimi, H. and Komatsu, K. (2001) Molecular analysis of medicinally-used Chinese and Japanese Curcuma based on 18S rRNA and trnK gene sequences. Biol. Pharm. Bull. 24, 1389-1394.

Dowling, T. E., Moritz, C., Palmer, J. D. and Rieseberg, L. H. (1996) Nucleic acids III: analysis of fragments and restriction sites; in Molecular Systematics, Hillis, D. M., Moritz, C. and Mable, B. K. (eds.), pp. 249-320, Sinauer Associates, Inc., Sunderland, USA

Doyle, J. J. and Doyle, J. L. (1987) A rapid DNA isolation procedure from small quantities of fresh leaf tissue. Phytochem. Bull. 19, 11-15.

Eksomtramage, L. and Boontum, K. (1995) Chromosome counts of Zingiberaceae. Songklanakarin J. Sci. Technol. 17, 291-297.

Eksomtramage, L., Sirirugsa, P. and Mayakul, S. (1996) Chromosome numbers of some Thai Zingiberaceae. Songklanakarin J. Sci. Technol. 18, 153-159.

Eksomtramage, L., Sirirugsa, P., Jivanit, P. and Maknoi, C. (2002) Chromosome counts of some Zingiberaceae species from Thailand. Songklanakarin J. Sci. Technol. 24, 311-319.

Fuguda, T., Yokoyama, J. and Ohashi, H. (2001) Phylogeny and biogeography of the genus Lycium (Solanaceae): inferences from chloroplast DNA sequences. Mol. Phylogent. Evol. 19, 246-258.

Gravendeel, B., Chase, M. W., De Vogel, E. F., Roos, M. C., Mes, T. H. M. and Bachmann, K. (2001) Molecular phylogeny of Coelogyne (Epidendroideae; Orchidaceae) based on plastid RFLPs, $m a t K$, and nuclear ribosomal ITS sequences: evidence for polyphyly. Am. J. Bot. 88, 1915-1927.

Hayashi, K., Yoshida, S., Utech, F. H. and Kawano, S. (2001) Molecular systematics in the genus Clintonia and related taxa based on $r b c L$ and matK gene sequence data. Plant Species Biol. 16, 119-137.

Hall, T. A. (1999) BioEdit: a user-friendly biological sequence alignment editor and analysis program. http://www.mbio.ncsu. edu/BioEdit/bioedit.html

Huang, S.-F., Hwang, S.-Y., Wang, J.-C. and Lin, T.-P. (2004) Phylogeography of Trochodendron aralioides (Trochodendraceae) in Taiwan and its adjacent areas. J. Biogeogr. 31, 1251-1259.

Kimura, M. (1980) A simple method for estimating evolutionary rates of base substitutions through comparative studies of nucleotide sequences. J. Mol. Evol. 16, 111-120.

Kress, W. J., Prince, L. M. and Williams, K. J. (2002) The phylogeny and a new classification of the gingers (Zingiberaceae): evidence from molecular data. Am. J. Bot. 89, 1682-1696.

Kress, W. J., Wurdack, K. J., Zimmer, E. A., Weigt, L. A. and Janzen, D. H. (2005) Use of DNA barcodes to identify flowering plants. Proc. Natl. Acad. Sci. USA 102, 8369-8374.

Loesener, T. (1930) Zingiberaceae; in Die natürlichen Pflanzenfamilien, Engler, A. and Prantl, K. (eds.), pp. 541-640, Leipzig, Germany.

Moorhead, S. M., Dykes, G. A. and Cursons, R. T. (2003) An SNP-based PCR assay to differentiate between Listeria monocytogenes lineages derived from phylogenetic analysis of the sigB gene. J. Microbiol. Meth. 55, 425-432.

Miles, K., McAuliffe, L., Ayling, R. D. and Nicholas, R. A. J. (2004) Rapid detection of Mycoplasma dispar and M. bovirhnis using allele specific polymerase chain reaction protocols. FEMS Microbiol. Lett. 241, 103-107.

Murakami, A., Ohigashi, H. and Koshimizu, K. (1994) Possible anti-tumor promoting properties of traditional Thai food items and some of their active constituents. Asia Pac. J. Clin. Nutr. 3, 185-191.

Ngamriabsakul, C., Newman, M. F. and Cronk, Q. C. B. (2003) The phylogeny of tribe Zingibereae (Zingiberaceae) based on ITS (nrDNA) and trnL-F (cpDNA) sequences. Edinburgh $J$. Bot. 60, 483-507.

Nishikawa, T., Salomon, B., Komatsuda, T., von Bothmer, R. and Kadowaki K.-I. (2002) Molecular phylogeny of the genus Hordeum using three chloroplast DNA sequences. Genome 45, 
1157-1166.

Saensouk, S. and Larsen, K. (2001) Boesenbergia baimaii, a new species of Zingiberaceae from Thailand. Nord. J. Bot. 21, 595597.

Sambrook, J. and Russell, D. W. (2001) Molecular Cloning: A Laboratory Manual, 3rd ed., Cold Spring Harbor Laboratory Press, New York, USA.

Samuel, R., Stuessy, T. F., Tremetsberger, K., Baeza, C. M. and Siljak-Yakovlev, S. (2003) Phylogenetic relationships among species of Hypochaeris (Asteraceae, Cichorieae) based on ITS, plastid trnL intron, trnL-F spacer, and matK sequences. Am. J. Bot. 90, 496-507.

Sang, T., Crawford, D. J. and Stuessy, T. F. (1997) Chloroplast DNA phylogeny, reticulate evolution, and biogeography of Paeonia (Paeoniaceae). Am. J. Bot. 84, 1120-1136.

Shaw, J., Lickey, E. B., Beck, J. T., Farmer, S. B., Liu, W., Miller, J., Siripun, K. C., Winder, C. T., Schilling E. E. and Small R. L. (2005) The tortoise and Hare II: relative utility of 21 noncoding chloroplast DNA sequences for phylogenetic analysis. Am. J. Bot. 92, 142-166.

Sirirugsa, P. (1992) A revision of the genus Boesenbergia Kuntze (Zingiberaceae) in Thailand. Nat. Hist. Bull. Siam Soc. 40, 6790.

Soltis, D. E., Kuzoff, R. K., Conti, E., Gornall, R. and Ferguson, K. (1996) $M a t K$ and $r b c L$ gene sequence data indicate that Saxifraga (Saxifragaceae) is polyphyletic. Am. J. Bot. 83, 371382.

Soltis, D. E., Tago-Nakazawa, M., Xiang, Q.-Y., Kawano, S., Murata, J., Wakabayashi, M. and Hibsch-Jetter, C. (2001) Phylogenetic relationships and evolution in Chrysosplenium (Saxifragaceae) based on $m a t K$ sequence data. Am. J. Bot. 88, 883-893.

Swangpol, S. (2004) Phylogeny of Kluai Tani (Musa balbisiana Colla), its related cultivars and hybrids based on DNA analysis. Ph.D. Thesis. Chulalongkorn University. p. 112.

Swofford, D. L. (2004) PAUP*: Phylogenetic Analysis Using
Parsimony (* and Other Methods) version 4.0 Beta 10. Sinauer Associates Inc., Sunderland, MA, USA.

Takano, A. and Okada, H. (2002) Multiple occurrences of triploid formation in Globba (Zingiberaceae) from molecular evidence. Plant Syst. Evol. 230, 143-159.

Tewtrakul, S., Subhadhirasakul, S. and Kummee, S. (2003) HIV-1 protease inhibitory effects of medicinal plants used as self medication by AIDS patients. Songklanakarin J. Sci. Technol. 25, 239-243.

Thaewnon-ngiw, B., Klinbunga, S., Phanwichien, K., Sangduen, N., Lauhajinda, N. and Menasveta, P. (2004) Genetic diversity and molecular markers of introduced and native apple snails (Genera Pomacea and Pila) in Thailand. J. Biochem. Mol. Biol. 37, 493-502.

Trakoontivakorn, G., Nakahara, K., Shinmoto, H., Takenaka, M., Onishi-Kameyama, M., Ono, H., Yoshida, M., Nagata, T. and Tsushida, T. (2001) Structural analysis of a novel antimutagenic compound, 4-hydroxypanduratin $\mathrm{A}$, and the antimutagenic activity of flavonoids in a Thai spice, Fingerroot (Boesenbergia pandurata Schult.) against mutagenic heterocyclic amines. $J$. Agr. Food Chem. 49, 3046-3050.

Tuchinda, P., Reutrakul, V., Claeson, P., Pongprayoon, U., Sematong, T., Santisuk, T. and Taylor, W. C. (2002) Antiinflammatory cyclohexenyl chalcone derivatives in Boesenbergia pandurata. Phytochemistry 59, 169-173.

Vanijajiva, O., Sirirugsa, P. and Suvachittanont, W. (2005) Confirmation of relationships among Boesenbergia (Zingiberaceae) and related genera by RAPD. Biochem. Syst. Ecol. 33, 159170 .

Vanijajiva, O., Suvachittanont, W. and Sirirugsa, P. (2003) Isozyme analysis of relationships among Boesenbergia (Zingiberaceae) and related genera in southern Thailand. Biochem. Syst. Ecol. 31, 499-511.

Winkworth, R. C., Grau, J., Roberton, A. W. and Lockhart, P. J. (2002) The origins and evolution of the genus Myosotis L. (Boraginaceae). Mol. Phylogenet. Evol. 24, 180-193. 